\title{
CICLOESTRATIGRAFIA NA BACIA INTRACRATÔNICA DO AMAZONAS
}

\author{
PAULO ROBERTO DA CRUZ CUNHA
}

\begin{abstract}
CYCLOSTRATIGRAPHY IN THE INTRACRATONIC AMAZONAS BASIN In this work the concepts of modern Sequence Stratigraphy are tentatively applied to an interior cratonic basin, while trying to refine the Early to Middle Devonian chronostratigraphy of the Amazonas Basin by using the Cyclostratigraphy techniques.

The author employed the following techniques to interpret the data and elaborate a coherent geologic model for the sedimentary section studied: (a) analysis and reconstructions of Devonian features interpreted from the comparison of biotic, ichnologic and lithologic data to extensive reference checking; (b) study of the tectonic and climatic conditions that affected Gondwana Supercontinent during the Early and Middle Devonian; (c) facies analysis and paleoenvironment interpretations based on core and cuttings descriptions, considering the fauna, ichnotypes, sediment texture and rock structures; (d) definition of sequence stratigraphic key-surfaces by using well logs, especially the gamma-ray log; and (e) orbital and climatic Cyclostratigraphy studies in order to check the influence of Earth's short orbital cycles on the sedimentary record by comparing the gamma-ray log spectra of the section studied to cycles of the Milankovitch frequency band.

The integration of these analyses allowed the construction of a chronostratigraphic framework for Early to Middle Devonian strata of the western portion of Amazonas Basin, comprising unit hierarchy, definition of depositional system tracts, sequence boundaries and other key-surfaces and the duration of events.

The main contributions of this work include the successful application of Sequence Stratigraphy concepts to a cratonic interior basin and the chronostratigraphic refinement obtained from orbital Cyclostratigraphy data analysis, which increases the accuracy of age estimates in at least one measurement order (from $10^{6}$ to $10^{5}$ years).
\end{abstract}

Key words: Cyclostratigraphy, cyclotheme, short eccentricity, spectral analysis, Milankovitch cyclicity, Early to Middle Devonian, Amazonas Basin.

\begin{abstract}
Resumo O trabalho foi desenvolvido com base em conceitos da moderna Estratigrafia de Seqüêências, buscando o refinamento cronoestratigráfico da seção rochosa do Devoniano Inferior e Médio da Bacia intracratônica do Amazonas, através da aplicação das técnicas da Cicloestratigrafia.

O autor montou um modelo geológico coerente para a seção estudada baseado em reconstruções paleogeográficas do Devoniano, inferidas de diferentes metodologias, incluindo: (a) investigação do conteúdo paleontológico e litológico; (b) estudo da tectônica e eustasia; (c) análises faciológicas, baseadas em afloramentos e testemunhos dos poços perfurados pela Petrobras; (d) definição de superfícies-chave da Estratigrafia de Seqüências através do uso de perfis elétricos e radioativos desses poços, especialmente o de raios-gama; e sobretudo (e) estudo dos registros climáticos impressos nos sedimentos, interpretados através das análises espectrais dos ciclos de excentricidade curta da órbita terrestre associados aos ciclos da banda de freqüências de Milankovitch.

A utilização da Cicloestratigrafia permitiu a construção de um arcabouço cronoestratigráfico para o Devoniano Inferior e Médịo da porção ocidental da Bacia do Amazonas, analisando-se suas unidades estratigráficas dentro de uma hierarquia sistematizada através da definição de superfícies-chave, definição de limites de seqüências e definição de tratos de sistemas deposicionais.

As principais contribuições do trabalho são demonstrar a aplicabilidade dos conceitos da moderna Estratigrafia de Seqüências em bacias sedimentares intracratônicas e a possibilidade do refinamento cronoestratigráfico, valendo-se da Cicloestratigrafia que, nesse caso particular, permitiu melhorar a aferição temporal em pelo menos uma ordem de grandeza, passando-se de $10^{6}$ anos, (1 Ma, da Paleontologia), para $10^{5}$ anos (100 ka, dos ciclos de excentricidade curta da órbita terrestre).
\end{abstract}

Palavras-chave: Cicloestratigrafia, análise espectral, ciclotema, Bacia do Amazonas, excentricidade curta, ciclos de Milankovitch.

\begin{abstract}
INTRODUÇÃo A Cicloestratigrafia usada no refinamento cronoestratigráfico da seção eo- a mesodevoniana da Bacia do Amazonas, na sua porção ocidental, serve para a comprovação da sua aplicabilidade no interior cratônico, tomando-se como base os ciclos de $4^{\mathrm{a}}$ e $5^{\mathrm{a}}$ ordens da moderna Estratigrafia de Seqüências. A área estudada compreende a parte ocidental da bacia, representada na fig. 01, estendendo-se desde a região de Manaus, no Estado do Amazonas, até as proximidades do Rio Tapajós, no Estado do Pará.

A seção rochosa estudada, representada na fig. 02 , foi definida informalmente como "Seqüência Urupadi" por Cunha (2000) e corresponde ao Grupo Urupadi (de $3^{\text {a }}$ ordem, composto pelas formaçỗes Maecuru e Ererê) e parte inferior do Grupo Curuá (Formação Barreirinha) que constituem parte da coluna estratigráfica da Bacia do Amazonas (Cunha et al., 1994).
\end{abstract}

Metodologia Procedeu-se o trabalho basicamente em duas fases: (a) o estudo da Estratigrafia de Sequiências, baseado nas análises das rochas, através de testemunhos, amostras de calha e perfis elétrico-radioativos de poços perfurados pela Petrobras, que permitiram a definição de marcos estratigráficos utilizados nas correlações regionais, nos estudos de afloraméntos, nas análises faciológicas, paleoambientais e paleogeográficas compiladas de levantamento bibliográfico acerca do Supercontinente Gondwana no Devoniano, do estudo do aporte sedimentar, da tectônica e da eustasia atuantes nesse tempo na bacia; todos em conjunto permitiram ao autor definir uma hierarquização dessas unidades em sequiências de todas as ordens (I a V); (b) o estudo da Cicloestratigrafia, baseado principalmente na análise paleoclimática do Devoniano, na relação com os parâmetros orbitais terrestres definidos pelos ciclos de Milankovitch e nas análises espectrais de perfis elétrico-radioativos de poços perfurados na bacia, pela Petrobras.

Esses dados, em conjunto com datações baseadas na palinologia e em invertebrados, permitiram a definição de um arcabouço cronoestratigráfico, refinado com o estudo da Cícloes- 
tratigrafia apoiada nas teorias de Milankovitch (1941) e que possibilitaram um maior detalhamento temporal das unidades.

A Seqüência Urupadi foi subdividida em ciclos menores ou Mesotemas (seqüências de $4^{\mathrm{a}}$ ordem) denominados de Seqüência Urupadi-1, Seqüência Urupadi-2 e Seqüência Urupadi-3 (Cunha, 2000), conforme ilustrado nas figuras 06, 07 e 08, cada

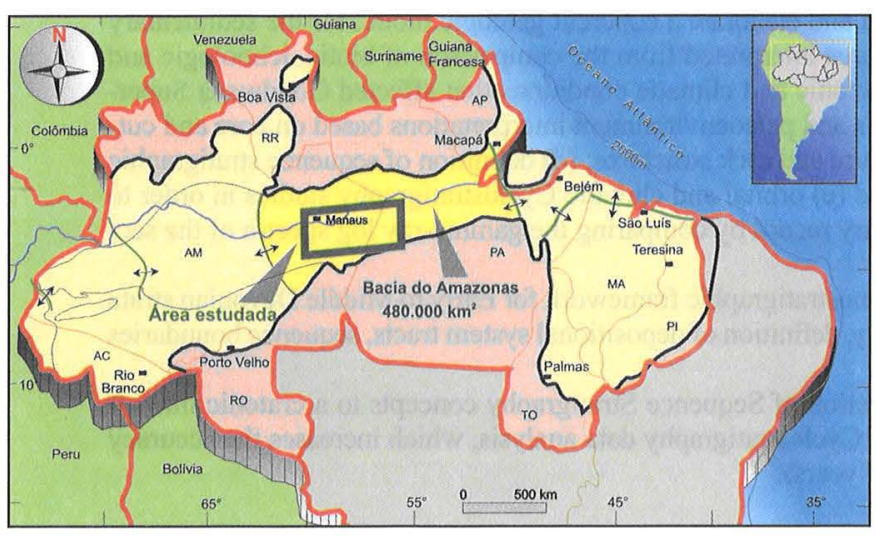

Figura 1 - Mapa de localização da Bacia do Amazonas e destaque da área estudada.

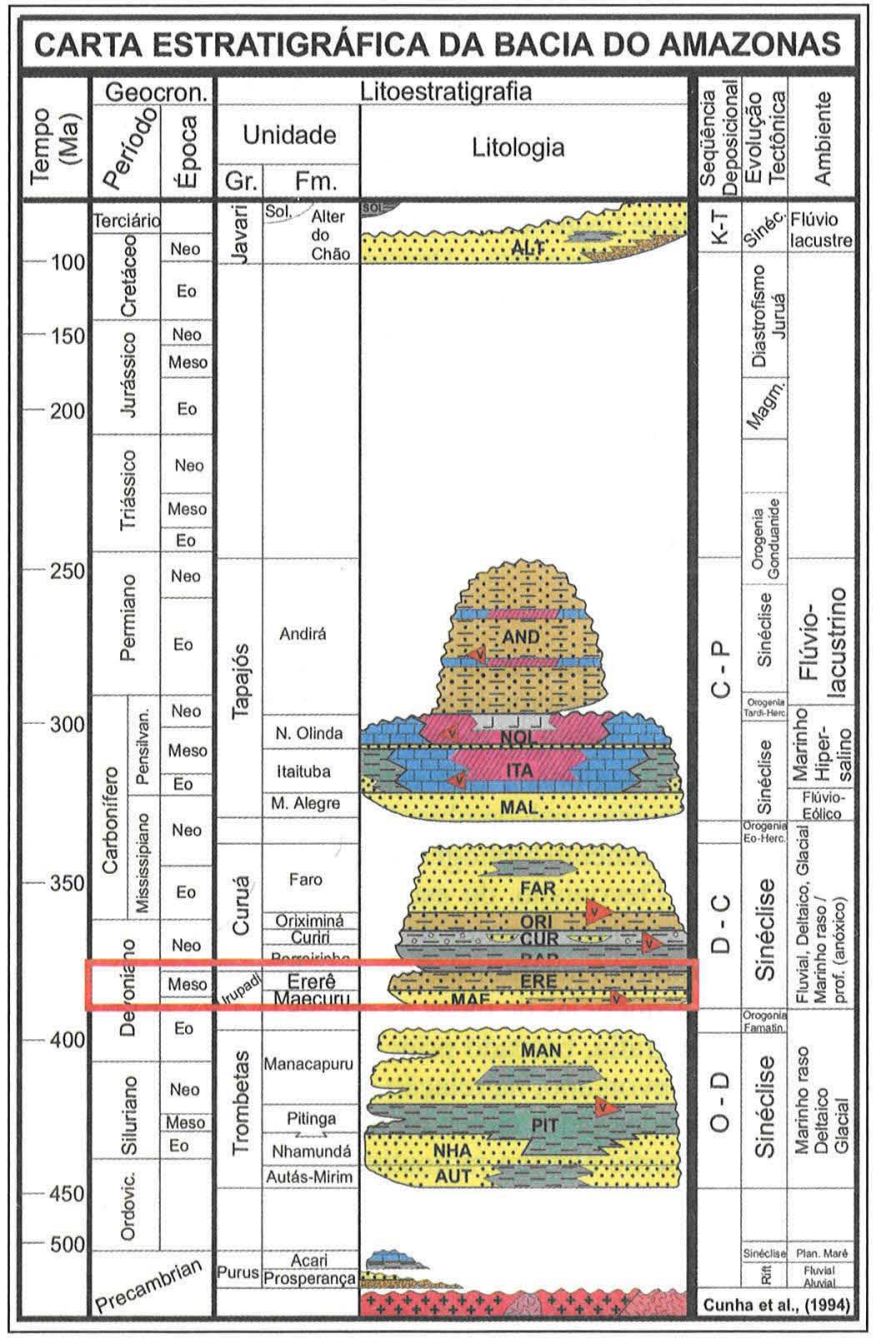

Figura 2 -Carta Estratigráfica da Bacia do Amazonas (Cunha et al., 1994) com destaque para a seção estudada. um deles constituído de vários Ciclotemas (seqüências de $5^{\text {a }}$ ordem). Estes, com o auxílio da interpretação dos registros geológicos impressos nos sedimentos e de acordo com as análises espectrais de perfis geofísicos de poços, puderam ter sua gênese relacionada com os processos climáticos, por sua vez afetados pelas variações da rotação e da excentricidade curta da órbita terrestre.

Dentro do contexto da Cicloestratigrafia, ramo da moderna Estratigrafia de Seqüências, foram interpretados ciclos de $5^{\text {a }}$ ordem, ou Ciclotemas, com duração temporal de cerca de 100 mil anos, uma ordem de grandeza mais acurada que as datações paleontológicas que alcançam 1 milhão de anos. A definição da duração dos ciclos foi aferida pela caracterização das parasseqüências e suas análises de séries temporais respectivas, associadas aos eventos climáticos resultantes das variações dos parâmetros orbitais da Terra, estudados pela Cicloestratigrafia, assunto principal deste trabalho.

\section{ESTRATIGRAFIA DE SEQÜÊNCIAS}

Generalidades Essa nova metodologia de análise estratigráfica deriva da Sismoestratigrafia, ferramenta que alcançou grande desenvolvimento com o avanço do "imageamento" sísmico de reflexão e o surgimento da sísmica digital. Sloss (1963) foi o pioneiro a utilizar o termo "seqüência" para separar os diversos ciclos de sedimentação nas plataformas cratônicas interiores do continente norte-americano, dando um cunho temporal a esses pacotes rochosos. O primeiro grande passo da Estratigrafia de Seqüências foi dado pelos trabalhos publicados no Memoir 26 da AAPG, em 1977, com ênfase na Sismoestratigrafia, onde a curva de variação do nível do mar ("curva de Vail", in Vail et al., 1977) se tornaria famosa no mundo inteiro. O grande impulso para a aceitação, desenvolvimento, ampla difusão e aplicabilidade dos conceitos da moderna Estratigrafia de Seqüências foi dado através da publicação do SEPM-42 (Wilgus et al., 1988) onde uma quantidade notável de trabalhos foi divulgada.

O registro estratigráfico é controlado pela interação de quatro variáveis principais: (1) tectonismo, que cria o espaço onde os sedimentos são depositados; (2) eustasia, responsável pelo padrão dos estratos e pelas litofácies; (3) aporte sedimentar, que controla a paleobatimetria, e (4) clima, que controla o tipo de sedimentação. Os fenômenos tectônicos e eustáticos, em conjunto, podem causar mudanças relativas do nível do mar que, por sua vez, controlam o espaço disponível para a deposição dos sedimentos. Tectonismo e clima controlam o volume e o tipo de sedimentos. O aporte sedimentar determinará o quanto de espaço disponível será preenchido.

Um breve resumo dessas quatro variáveis principais, afetando o registro estratigráfico devoniano, é reportado a seguir, sendo as duas primeiras retratadas de imediato e as duas últimas dentro do assunto destacado, a posteriori, como Cicloestratigrafia.

Tectônica no Devoniano A tectônica desenvolvida nas bacias setentrionais do Supercontinente Gondwana durante o Devoniano foi de intensidade moderada: os eventos orogênicos Herciniano e Mauritanides tiveram pouca atuação além de suas próprias faixas móveis, não atingindo as bacias relativamente longínquas do interior cratônico, como as do Amazonas e Parnaíba, no Brasil, e Murzuk, na Líbia. Devido à orogenia incipiente, a sedimentação foi lenta e associada a um substrato relativamente estável e raso, com depósitos formando extensos lençóis, típicos de áreas epicontinentais.

A análise das curvas de subsidência da história deposicional da Bacia do Amazonas reflete movimentação cíclica, onde se alternam episódios de subsidência mais e menos acentuada, dentro de um contexto de fraco regime de stress e de forças distantes da bacia sedimentar (fig. 03). A duração de tais ciclos, da ordem 


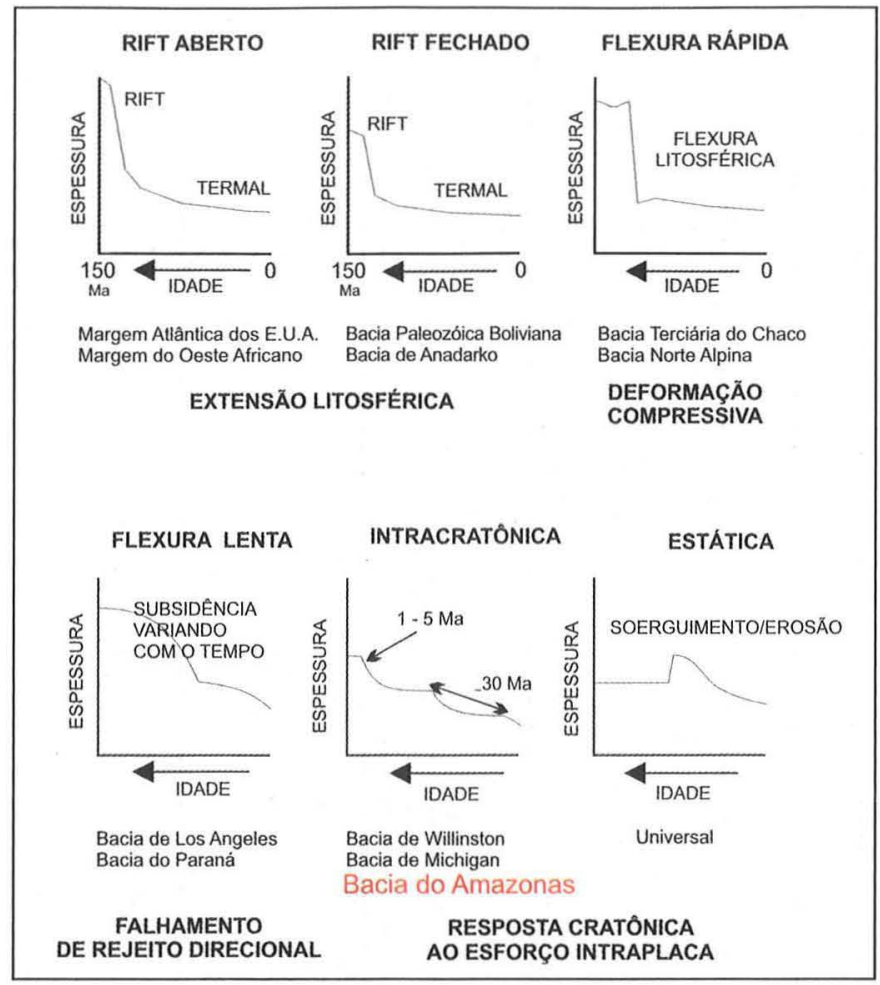

Figura 3 - Curvas típicas de subsidência tectônica para vários estilos estruturais (modif. de Williams, 1995).

de dezenas de milhões de anos, permite associá-las a unidades estratigráficas de ordem II (Superciclos ou Superseqüências) e possui boa correlação com as bacias de Willinston, Michigan e Permian (Williams, 1995) (fig. 04). Estudos tectônicos efetuados na Bacia do Amazonas (Coutinho \& Gonzaga, 1994) mostram pequenos pulsos de subsidência tectônica à semelhança das curvas de Williams (fig. 05).

A tectônica de placas pode e deve ser aplicada ao Devoniano. As reconstruções paleogeográficas e paleomagnéticas confirmam a movimentação do Supercontinente Gondwana e da Euramérica para o Norte. Há evidências de contínua subida do nível do mar associada provavelmente ao acentuado e rápido crescimento do assoalho oceânico (cordilheiras meso-oceânicas) e formação de crosta oceânica. Essas mudanças do nível do mar interagiram com os movimentos epirogenéticos observados nas sucessões estratigráficas do Gondwana. As deformações foram sutis nos crátons Brasileiro e Patagoniano ocasionando extensos lençóis de rochas clásticas correlacionadas regionalmente, refletindo o tectonismo insignificante durante o Devoniano.

Eustasia no Devoniano Eustasia é o movimento de subida ou descida do nível do mar que pode ser inferido por vários métodos. Há dois tipos de eustasia: a tectono-eustasia e a glácio-eustasia. A primeira está relacionada às mudanças nos volumes d'água das bacias oceânicas, condicionadas pelo volume de material ígneo formado nas cordilheiras meso-oceânicas e pela taxa de criação do assoalho oceânico; quanto mais rápida a criação da crosta oceânica, menor será a profundidade média das bacias, causando a subida do nível do mar e a conseqüente invasão sobre os continentes; a segunda é originada pela mudança do volume d'água presente nos oceanos, relacionada aos períodos glaciais e inter-glaciais; quando as geleiras sobre os continentes podem incorporar ou liberar grandes volumes de água em reduzidos intervalos de tempo. A glácio-eustasia gera ciclos transgressivo-regressivos de segunda a quinta ordens com

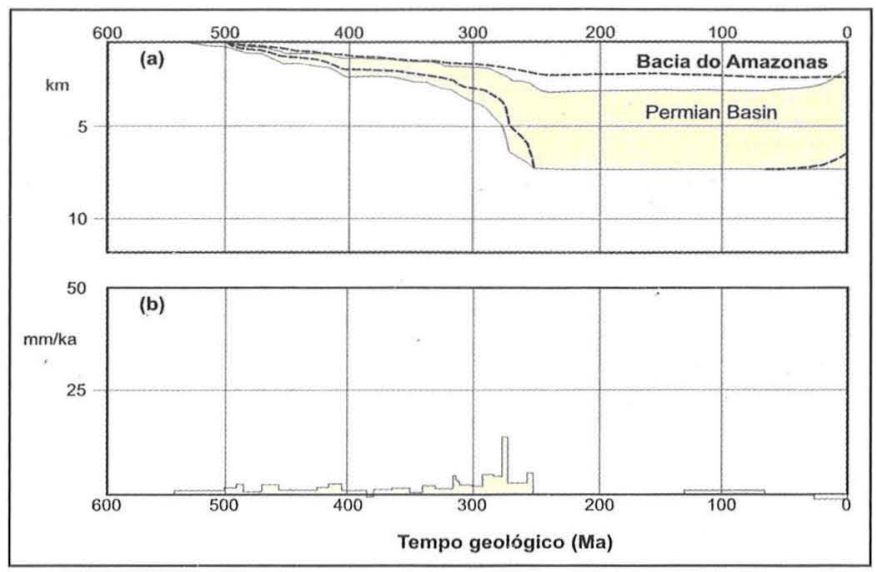

Figura 4 - Curvas tectônicas ("backstripping") comparativas entre a Bacia do Amazonas e a Permian Basin. a) padrão deposicional; b) taxa de subsidência do embasamento (Williams, 1995).

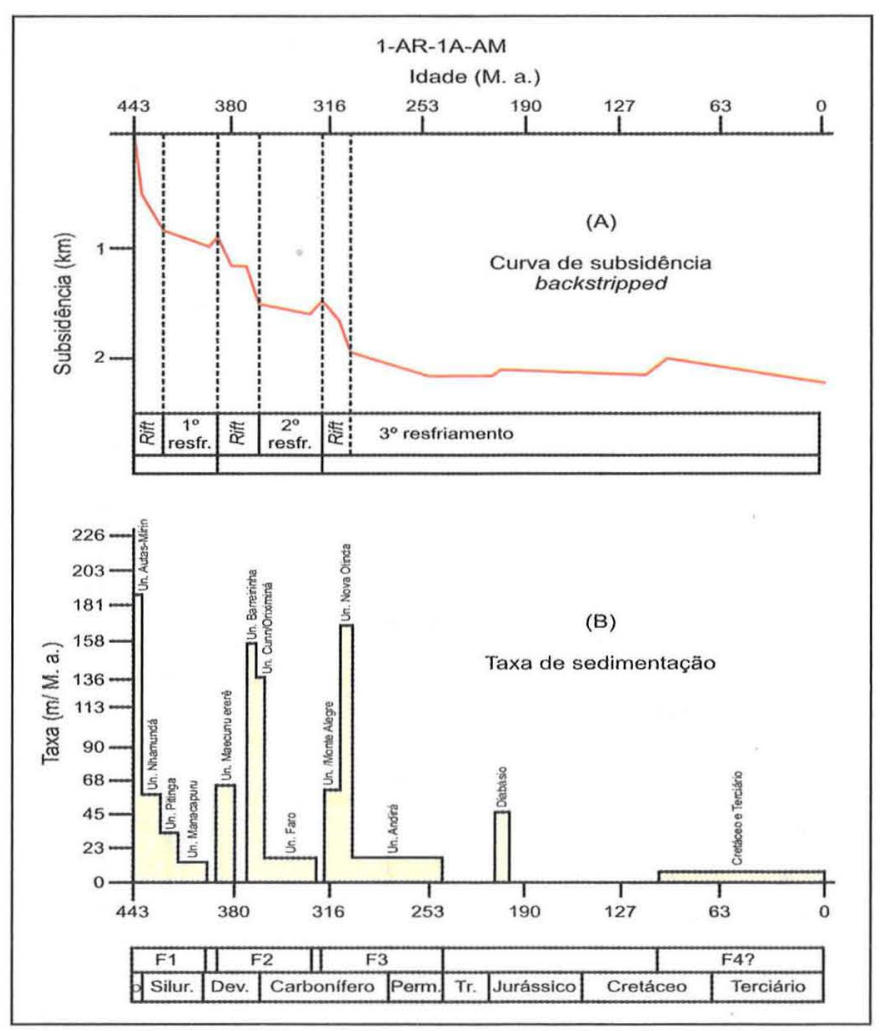

Figura 5 - Curvas de taxas de subsidências das seqüências da Bacia do Amazonas (Coutinho \& Gonzaga, 1994).

menor magnitude, mas com mais alta freqüência que aqueles induzidos por tectonismo.

Com base no zoneamento de conodontes, Johnson et al. (1985) estabeleceram, para a Euramérica, uma curva de variação do "onlap" costeiro, contendo ciclos transgressivo-regressivos de natureza eustática. Cunha (2000) analisou os ciclos eo- a mesodevonianos da Bacia do Amazonas, associando-os com as variações apresentadas na curva mencionada (fig. 06), e os correlacionou, ainda, com os ciclos da Bacia do Parnaíba.

Arcabouço Estratigráfico-Hierarquia A Bacia do Amazonas possui um arcabouço estratigráfico bem estabelecido, con- 


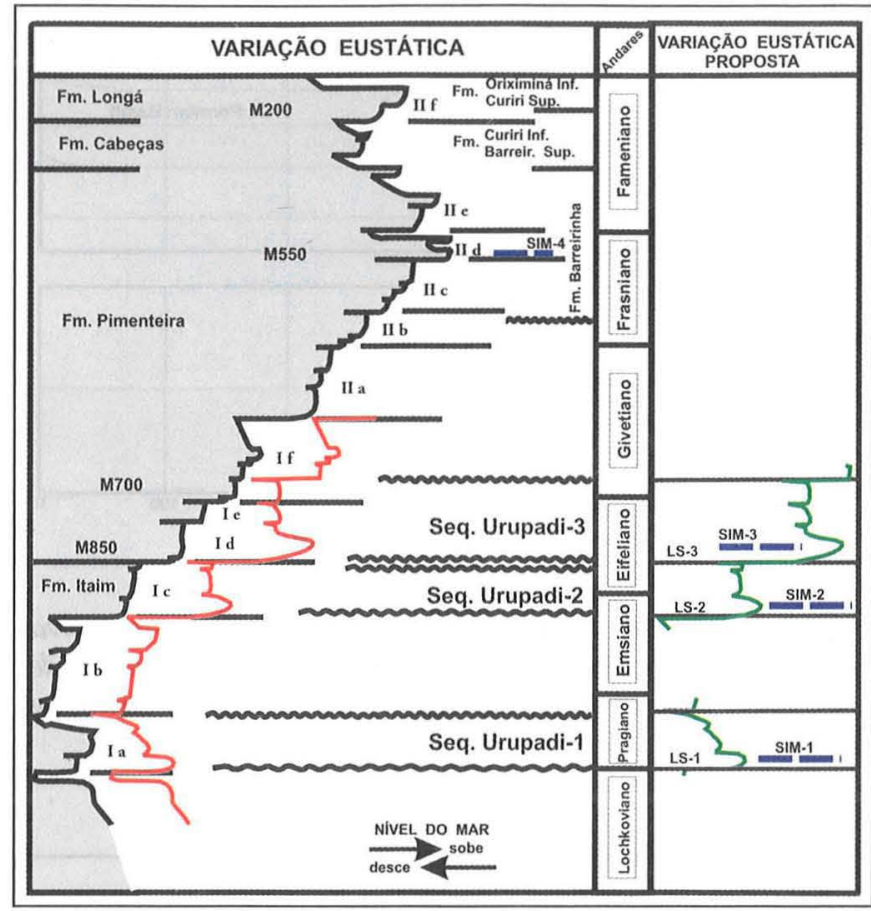

Figura 6 - Curva de variação do "onlap" costeiro para o Devoniano (modif. de Jonhson et al., 1985), a curva de variação eustática proposta para o Eo-mesodevoniano da Bacia do Amazonas e a correlação das seqüências de ordem IV (Urupadi-1, 2 e 3) interpretadas por Cunha (2000) com as da Bacia do Parnaiba.

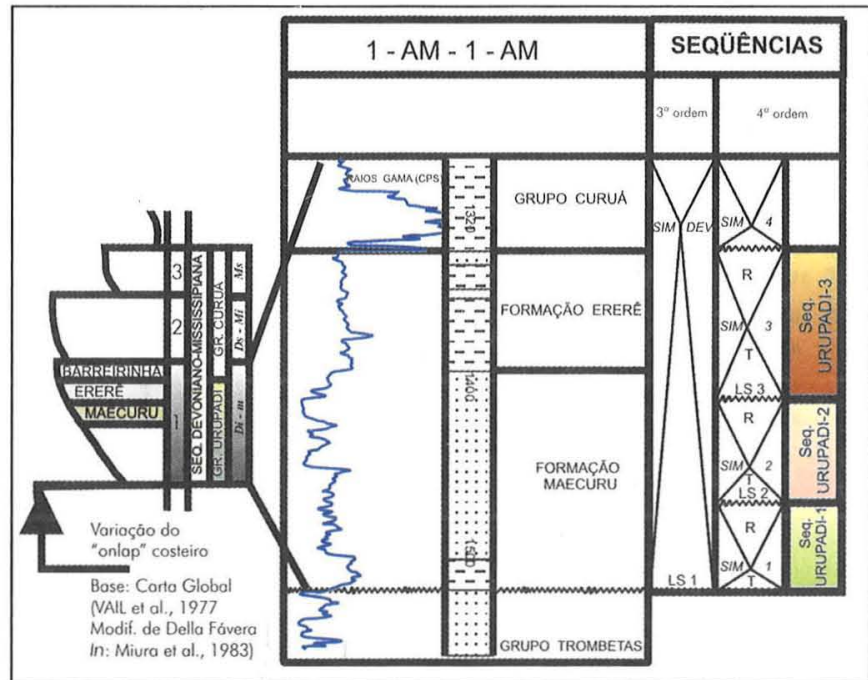

Figura 7 - Subseqüências (de ordem III) da Seqüência Devoniano-Mississipiana (ordem II) segundo Della Fávera (in Miúra et al., 1983) e as seqüências de ordens III e IV segundo Cunha (2000).

siderando seus aspectos litoestratigráficos, fruto de mais de um século de investigações efetuadas por dezenas de geólogos que atuaram na bacia. Com relação aos seus limites cronoestratigráficos, entretanto, a bacia ainda carece de estudos mais aprofundados. Este trabalho é uma contribuição nesta linha de pesquisa, aplicando-se a moderna Estratigrafia de Seqüências a uma parte do prisma sedimentar da bacia, mais precisamente aquela correspondente à sua fase evolutiva eo- a mesodevoniana.

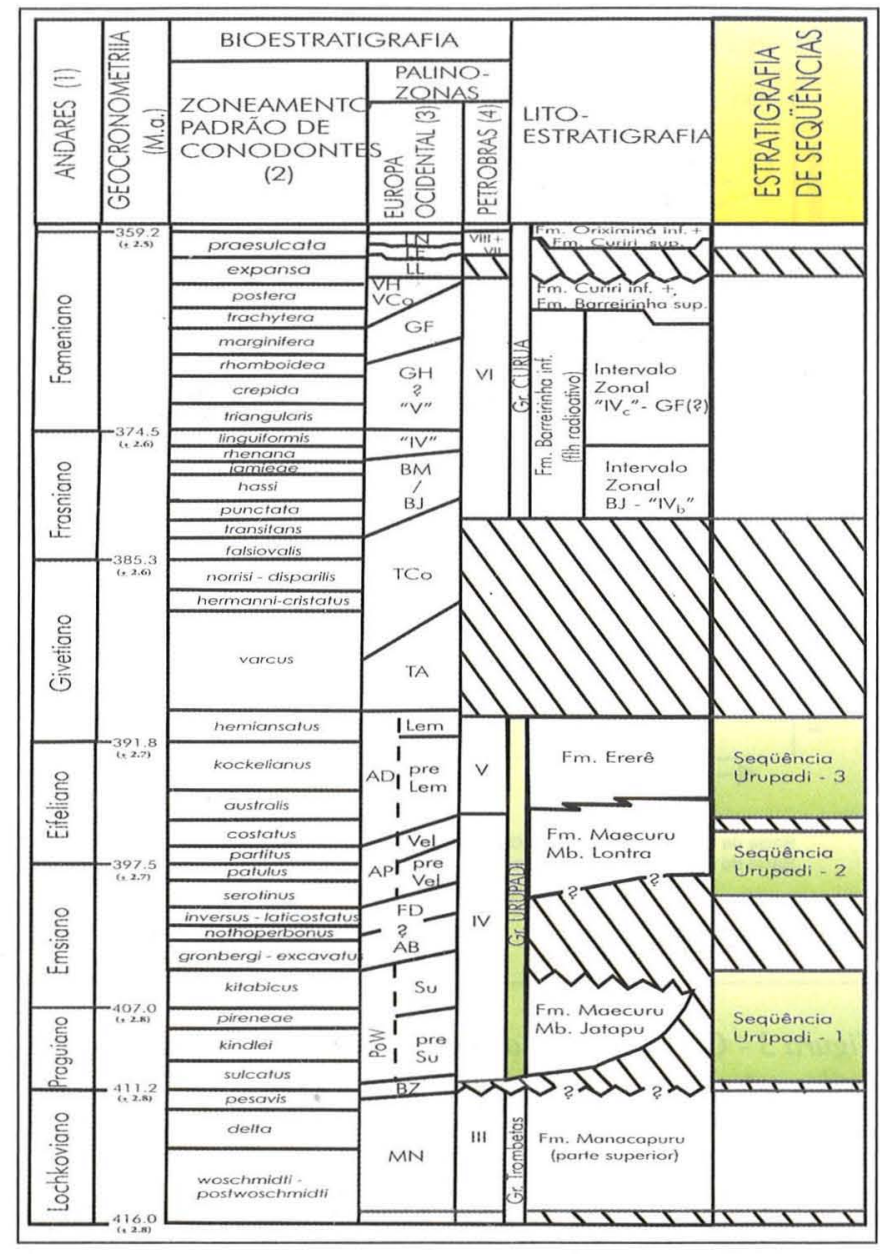

Figura 8 - Interpretação das seqüencias de ordens III (Gr. Urupadi) e IV (Urupadi-1, Urupadi-2 e Urupadi-3) dentro do arcabouço bioestratigráfico (modif. de Cunha, 2000). Geocronometria e zoneamento padrão de conodontes do Devoniano atualizados segundo Gradstein et al. (2004).

Considerou-se inicialmente, com modificações, a última Carta Estratigráfica da Bacia do Amazonas (Cunha et al., 1994) (fig. 02). O registro paleozóico da bacia inclui estratos depositados entre o Neo-Ordoviciano e o Neopermiano, compondo uma unidade ou Megasseqüência de ordem I, ou de primeira ordem (Vail et al., 1991). Esses sedimentos estão sobrepostos por outra Megasseqüência, composta por sedimentos neocretáceos a terciários.

A Megasseqüência paleozóica (de ordem I), totalizando um intervalo temporal de cerca de 200 milhões de anos (200 Ma), não constitui um registro deposicional contínuo, pois engloba múltiplas condições tectono-sedimentares. Desse modo, pode ser dividida em um conjunto de três Superseqüências (ordem II), distribuídas de modo descontínuo entre os limites temporais correspondentes à base e ao topo da unidade de ordem I. Essas unidades, de ordem II, apresentam-se como pacotes rochosos separados por discordâncias regionais. Constituem-se nas verdadeiras Seqüências de Sloss (1963), ou Sintemas (Chang, 1975), cada uma delas relacionadas às diferentes condições tectono-sedimentares. As superseqüências de ordem II representam os ciclos de maior amplitude espacial e temporal do arcabouço tectono-estratigráfico da bacia, aos quais se atribui uma evolução contínua, compreendendo contextos deposicionais geneticamente relacionados.

Quatro unidades aloestratigráficas de segunda ordem ou Su- 


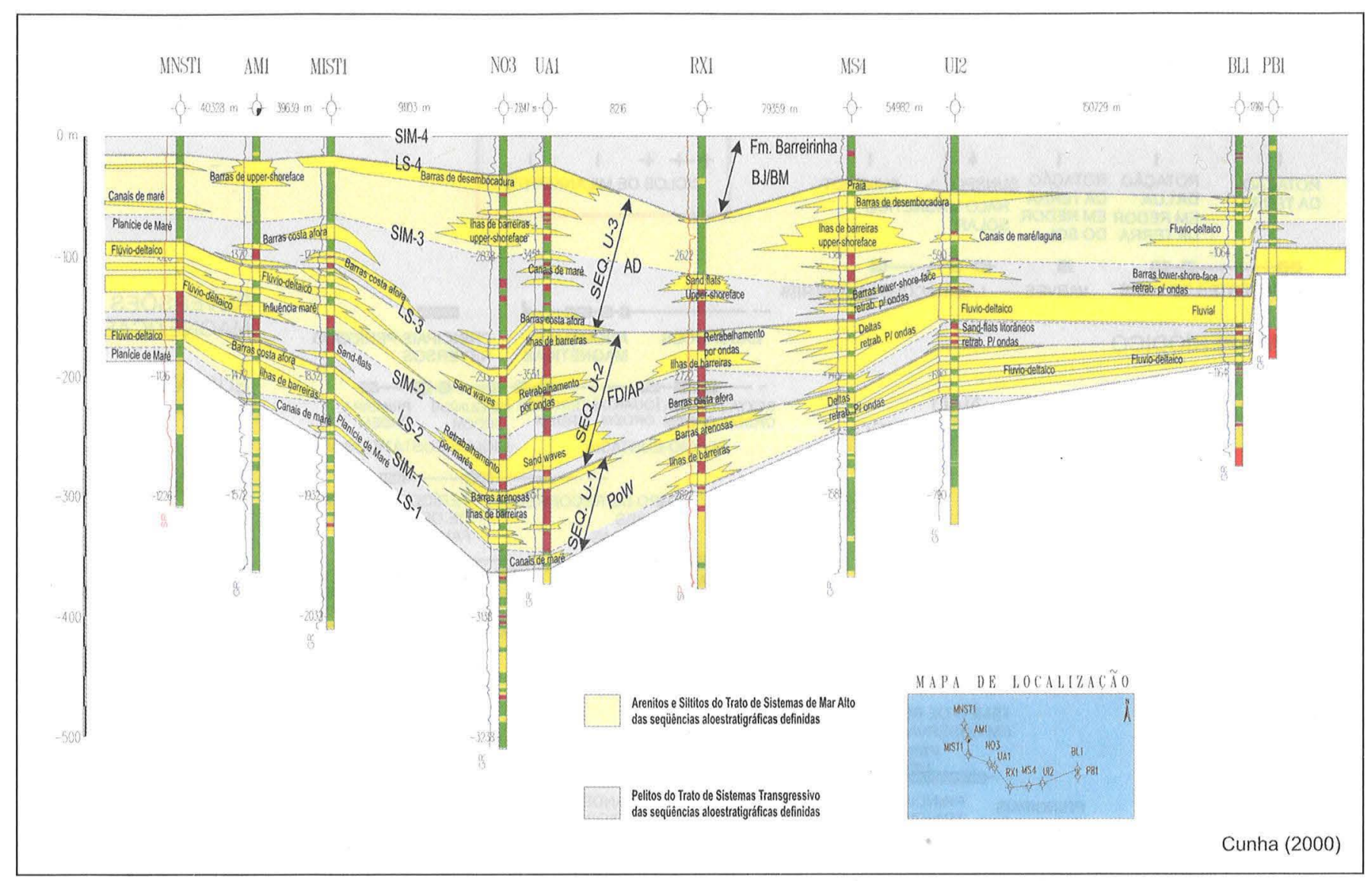

Figura 9 - Seção geológica regional destacando as litofácies, superficies-chave, e a definição de seqüências de ordem IV (Urupadi1, Urupadi-2 e Urupadi-3).

perseqüências (Cunha et al., 1994) são reconhecidas na bacia, três das quais representadas por ciclos transgressivo-regressivos paleozóicos, e uma do Mesozóico-Cenozóico, esta constituída por sedimentos continentais; ocorrem, ainda, rochas ígneas intrusivas (fig. 02).

As seqüências de ordem III, IV e V serão discutidas a seguir, levando-se em consideração que essas análises se alicerçaram na aplicabilidade dos conceitos da moderna Estratigrafia de Seqüências e na Cicloestratigrafia.

Essa metodologia de análise estratigráfica de sucessões rochosas, de ordem III, IV e V, foi aplicada na seção eo- a mesodevoniana da Bacia do Amazonas por Cunha (2000), que relacionou o arcabouço aloestratigráfico dessa seção com o Grupo Urupadi e porção basal do Grupo Curuá, constituintes da coluna litoestratigráfica da bacia (Cunha et al., 1994).

O Grupo Urupadi é constituído pelas formações Maecuru (Membros Jatapu e Lontra) e Ererê que, juntas à Formação Barreirinha (parte basal do Grupo Curuá), compõem uma seqüência de ordem III, de acordo com a concepção de Della Fávera (in: Miura et al., 1983) que as considerou como componentes da Subseqüência I (de ordem III) da então Seqüência DevonianoMississipiana (de ordem II), baseado na variação do nível do “onlap" costeiro de Vail et al. (1977) (fig. 07).

O Grupo Urupadi foi dividido em três seqüências de ordem IV, de acordo com as premissas da moderna Estratigrafia de Seqüências. Cada uma das seqüências de ordem IV (definidas informalmente como Seqüência Urupadi-1, Urupadi-2 e Urupadi3 , segundo Cunha, 2000) é composta por um trato de sistemas de mar baixo/transgressivo e um trato de sistemas de mar alto, sendo bem individualizadas as superfícies de inundação máxima (definidas pelos folhelhos radioativos regionalmente espalhados na bacia), bem como os limites de seqüências. O trato de sistemas de mar baixo é de difícil interpretação, sendo postulada a sua existência pela análise de afloramentos da borda sul da bacia onde ocorre fácies de alta energia representada por arenitos fluviais (?) relacionados a possíveis "vales incisos" em períodos de regressão forçada, ou ainda coincidentes com feições associadas a "lags" transgressivos (fig. 09).

A Seqüência Urupadi-1 caracteriza-se pela sedimentação sob a forma de extensas planícies de maré retrogradacionais, assentadas sobre o Grupo Trombetas (Siluro-devoniano). Na área da Plataforma Sul da bacia, parece estar relacionada a depósitos continentais associados à borda fisiograficamente mais íngreme.

A Seqüência Urupadi-2 possui trato de sistemas transgressivo influenciado pela ação de ondas de tempestades. A ação de organismos bioturbadores durante os períodos de calmaria está documentada por icnofósseis mais característicos de lâmina d'água rasa. As fácies sedimentares mais representativas do trato regressivo, ou de nível de mar alto, são representadas por: barras arenosas de "lower-shoreface", cordões litorâneos ("foreshore sandwaves"), planície de maré, canais de maré ("inlet-channels"), compondo sistemas de ilha de barreira-estuário.

A Sequiência Urupadi-3 inicia com depósitos de barras de plataforma distal, evidenciando um rápido evento transgressivo. As estruturas internas dessas barras denunciam forte influência da ação de ondas de tempestades. A porção superior dessa unidade, correspondente ao trato de sistemas de mar alto, é caracterizada pela ocorrência de progradações deltaicas, notadamente na parte noroeste da área estudada. Esses depósitos possuem forte influência de ação de marés, principalmente na margem norte da bacia, onde o declive é mais suave, ao contrário da 


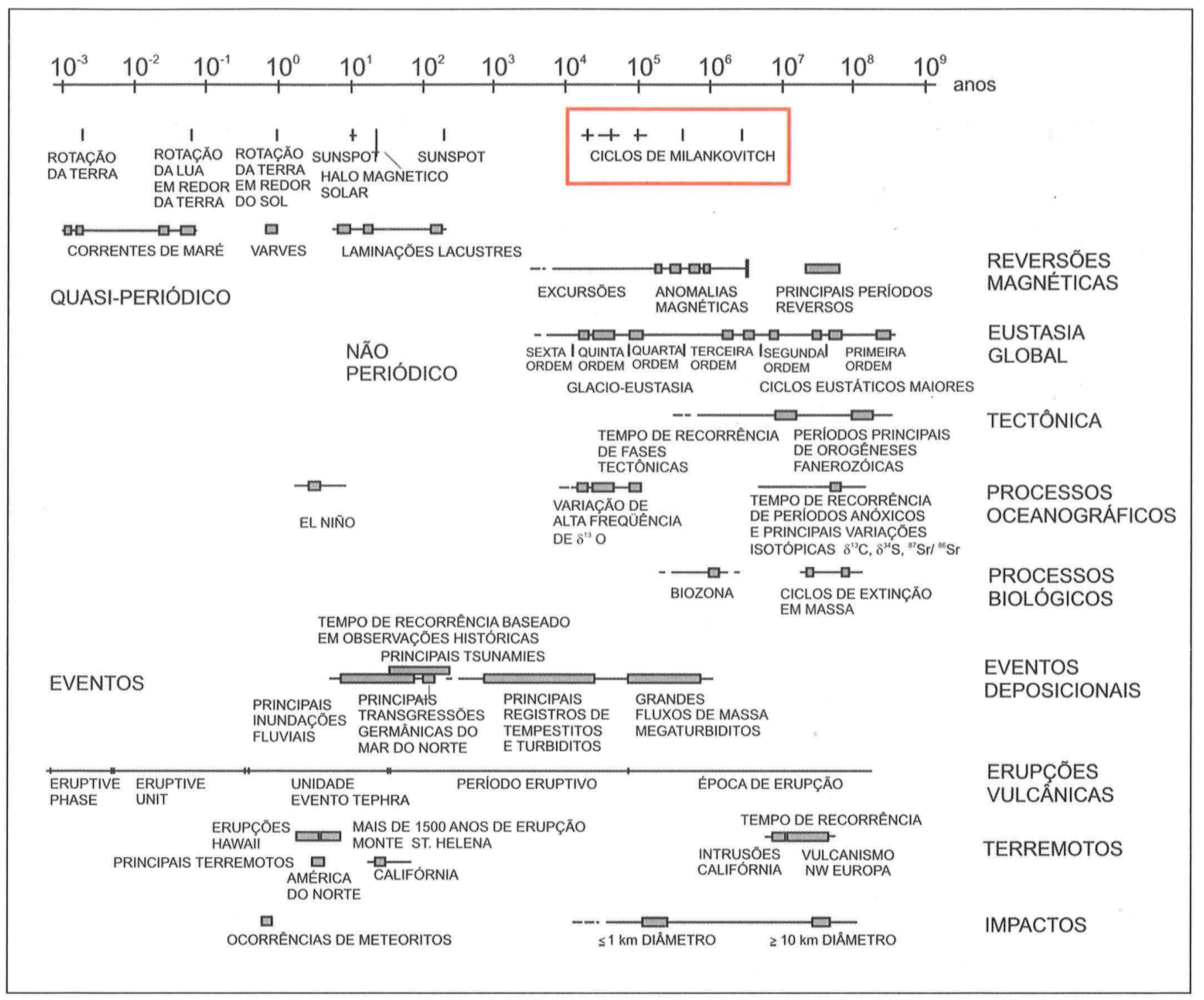

Figura 10 - Tempo de recorrência dos processos episódicos e periódicos e dos eventos geológicos (Einsele et al., 1991).

margem sul, onde o retrabalhamento dos sedimentos deveu-se à ação principal das ondas de tempestades, no contexto de uma fisiografia mais íngreme.

Todo esse trabalho de análise faciológica e de hierarquização das unidades estratigráficas em seqüências de várias ordens, associadas às superfícies-chave da Estratigrafia de Seqüências e às palinozonas, é resumido e visualizado na figura 09.

\section{CICLOESTRATIGRAFIA}

Generalidades A duração e freqüência dos eventos geológicos e a ciclicidade estratigráfica englobam, no mínimo, 16 ordens de magnitude, variando desde ciclos de curta duração, relacionados às correntes de turbidez $\left(10^{-6} \mathrm{a}\right)$, até os ciclos relacionados à tectônica de placas envolvendo a formação ou a ruptura de supercontinentes $\left(10^{9}\right.$ a) (Einsele et al., 1991) (fig. 10).

As ciclicidades de grande significado geológico, atualmente conhecidas como ciclicidades da banda de Milankovitch, variam de $10^{4}$ anos a $10^{5}$ anos (Miall, 1997). Estão ligadas às variações climáticas na Terra que foram provocadas (ou ao menos potencializadas) por mudanças na taxa de insolação do planeta, em virtude de alterações cíclicas nos componentes de sua órbita em redor do Sol (Milankovitch, 1941). A Teoria de Milankovitch estabelece o relacionamento causal entre os parâmetros astronômicos e as épocas glaciais, com a quantificação dos reflexos na insolação terrestre em função das variações na excentricidade, obliqüidade e precessão da órbita da Terra.

A mudança no clima afeta diretamente os processos e taxas de intemperismo, transporte e deposição, com reflexos no influxo de sedimentos na bacia e na produtividade biológica, entre outros fatores. Estas modificações ambientais, astronomicamente induzidas, se preservadas adequadamente nos sedimentos, definem unidades litológicas rítmicas, cujas variações de espessura podem expressar relações similares àquelas existentes entre os períodos conhecidos das variáveis orbitais da Terra (100ka para a excentricidade, $41 \mathrm{ka}$ para a obliqüidade e $21 \mathrm{ka}$ para a precessão).

Antes de entrarmos na discussão da análise espectral, faremos a seguir uma breve discussão sobre os dois outros parâmetros controladores das seqüências deposicionais, conforme discutido no item "Estratigrafia de Seqüências - Generalidades". São eles: o clima e o aporte sedimentar no Devoniano da Bacia do Amazonas.

Clima e aporte sedimentar no Devoniano O aporte sedimentar, que controla a paleobatimetria, preenche os espaços criados pela subida relativa do nível do mar. A assinatura estratigráfica 


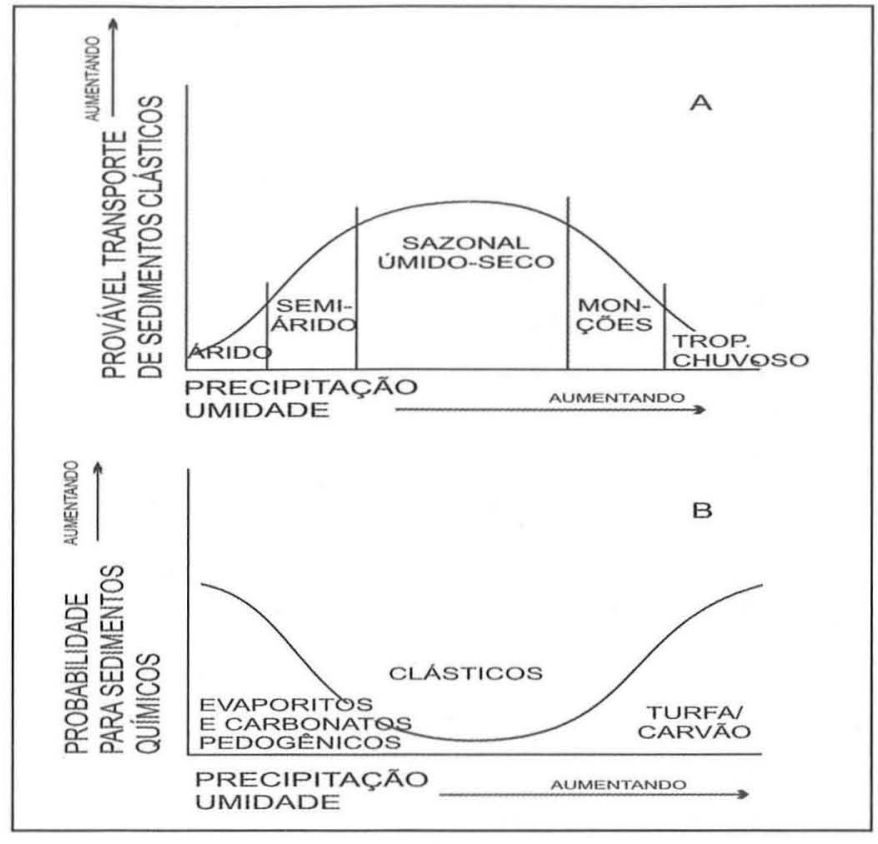

Figura 11 - Resposta sedimentológica às variações climáticas (Cecil, 1990).

dos efeitos sedimentológicos são os sistemas deposicionais, constituídos por lâminas, leitos e episódicas parasseqüências. Essas unidades contêm estruturas sedimentares relacionadas aos processos inerentes a cada ambiente deposicional, os quais são gerados pelo vento, ondas, fluxo de massas, marés, inundações, correntes marinhas e fluviais, precipitações e floculações, todos indubitavelmente afetados pelo regime climático atuante à época da deposição dos sedimentos.

Os principais elementos de análise paleoclimática são as rochas, os minerais que a constituem, os fósseis, os dados geoquímicos e os paleomagnéticos. Através dessas ferramentas pode-se inferir movimentações das placas tectônicas, a "posição" dos pólos e, conseqüentemente, o clima atuante em determinada região do globo durante sua mudança latitudinal através do tempo geológico.

O principal controle do clima global é a circulação atmosférica/oceânica que, por seu turno, controla a umidade, a freqüência das precipitações e a temperatura. Variações orbitais da Terra podem causar mudanças climáticas capazes de gerar ciclicidades sedimentares. Cecil (1990) estabeleceu um modelo geral de resposta do sistema deposicional às variações climáticas, no qual as migrações dos cinturões climáticos, induzidas por forças orbitais ou deslocamentos continentais através dos cinturões climáticos (decorrentes dos movimentos das placas tectônicas), resultariam em alterações climáticas que modificariam o suprimento de sedimentos clásticos e os padrões de sedimentação química (fig. 11).

Durante o Devoniano, os continentes América do Sul e África faziam parte de um mesmo supercontinente, denominado Gondwana, banhado ao norte por correntes subtropicais aquecidas do Mar de Tétis, estando a Bacia do Amazonas situada entre as latitudes $48^{\circ} \mathrm{S}$ e $57^{\circ} \mathrm{S}$, com base em indicadores paleomagnéticos, litológicos e faunísticos. Conseqüentemente, apresentava clima frio/temperado, variando de úmido a subúmido, dentro do cinturão climático 7a (Perlmutter \& Matthews, 1989) (fig. 12). Caracterizava-se por um aporte sedimentar essencialmente siliciclástico, com ausência de evaporitos e carbonatos, e por faunas marinhas mistas, em grande parte derivadas das províncias setentrionais da Euramérica, mas incluindo também elementos

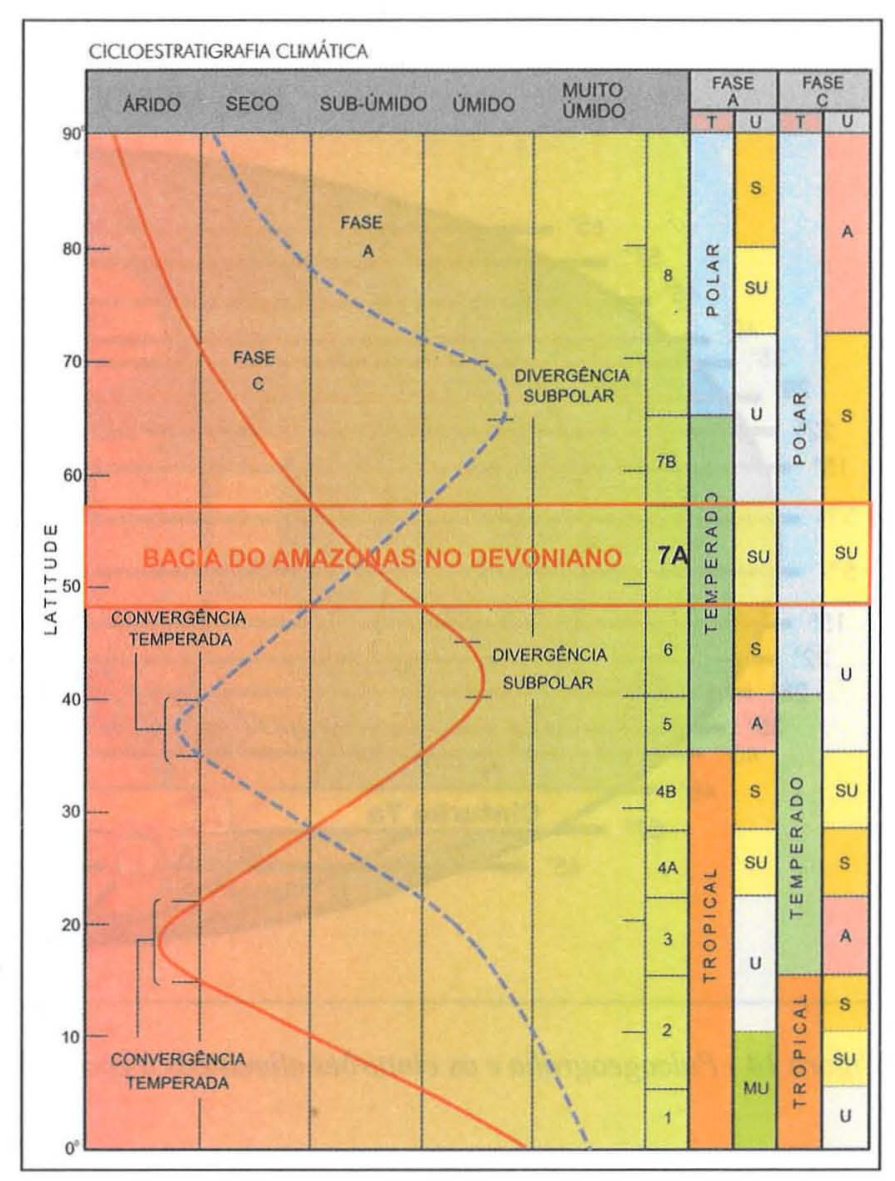

Figura 12 - Variações e fases climáticas com o posicionamento da Bacia do Amazonas no cinturão 7 A (Cunha, 2000 - modif. de Perlmutter \& Mathews, 1989).

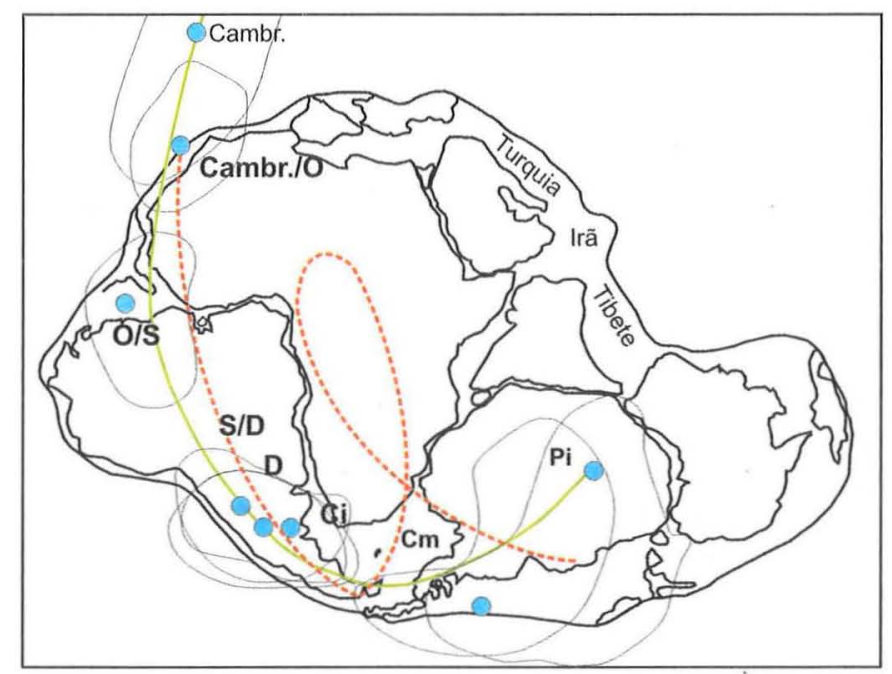

Figura 13 - "Trajetória polar aparente" no Gondwana (Scotese \& Barret, 1990).

"austrais” da Província Malvinocáfrica, de águas frias. Reconstituições paleomagnéticas da "trajetória polar aparente" através do Gondwana durante o Paleozóico (fig. 13) explicam a natureza siliciclástica da seção devoniana. Além disso, o conjunto das litofácies presentes na área estudada, interpretado através de afloramentos, testemunhos e correlações de perfis elétricos e radioativos dos poços perfurados, corrobora a reconstrução pa- 


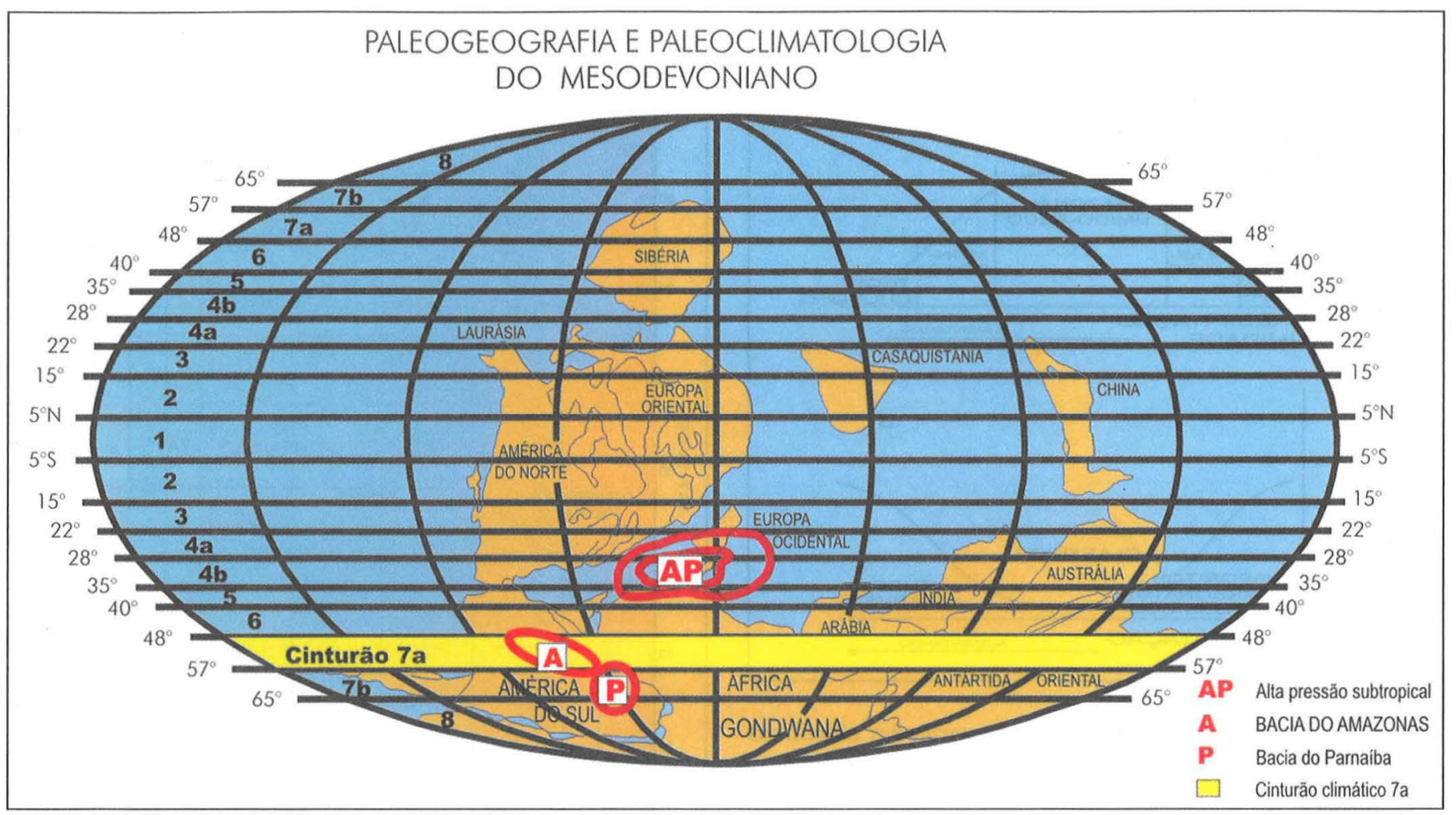

Figura 14 - Paleogeografia e os cinturões climáticos à época devoniana (Cunha, 2000 - modif. de Perlmutter \& Mathews, 1989).

leogeográfica da Bacia do Amazonas (fig. 14).

A análise espectral Hays et al. (1976) inauguraram a fase moderna da pesquisa sobre a relação entre os mecanismos orbitais da Terra e o clima, através da análise espectral de uma série de testemunhos do fundo do Oceano Índico. Suas análises identificaram períodos que estão de acordo com aqueles previstos pela Teoria de Milankovitch. Fischer (1986) classificou os ciclos sedimentares como autocíclicos e alocíclicos, e Einsele et al. (1991) criaram a Cicloestratigrafia, correlacionando as seqüências alocíclicas por longas distâncias, entre bacias e, até mesmo de um continente para outro.

A análise espectral é um método objetivo e estatístico usado para detectar ciclicidades regulares nos conjuntos de dados classificados como séries de tempo, e identificar a natureza dos fenômenos representados pelo objeto observado. A determinação dos ciclos e de seus períodos pode ser obtida através da análise espectral e da geração e interpretação de periodogramas. O periodograma registra, nas ordenadas, a densidade do espectro de potência e, nas abscissas, a freqüência de oscilações dos harmônicos, representada pela razão ciclo/intervalo de amostragem. O comprimento de onda ou o período de cada freqüência significativa é obtido dividindo-se o intervalo de amostragem pelo número de ciclos (Castro, 1999).

Identificados os ciclos e determinadas suas freqüências e comprimentos de ondas, por meio da análise de série temporal, pode-se estimar, para cada conjunto de dados, os prováveis parâmetros orbitais controladores dos alociclos. Utilizando-se de programa computacional de comparação de matrizes, chegase à correspondência entre razões dos diferentes comprimentos de onda destacados no periodograma e aquelas envolvendo os períodos orbitais de Milankovitch.

CICLICIDADE REGISTRADA E INTERPRETADA ATRAVÉS DE PERFIS Em qualquer estudo acerca de ciclicidade envolvendo análise espectral, independentemente da ferramenta empregada, os ciclos sedimentares de qualquer origem só podem ser registrados como padrões cíclicos em perfis quan- do o processo deposicional for contínuo e a taxa de acumulação dos sedimentos for considerada constante.

Avaliação estatística dos perfis dos poços Utilizou-se a análise espectral do perfil de raios-gama para testar a aplicabilidade da Teoria de Milankovitch, ou seja, checar a relação entre as variações climáticas ligadas aos fatores orbitais terrestres e as ciclicidades ou repetitividades registradas nas unidades estratigráficas eo- a mesodevonianas estudadas, mais precisamente nas parasseqüências (ciclos de ordem V ou ciclotemas) que compõem a Seqüência Urupadi-3 (de ordem IV).

A partir do arcabouço litoestratigráfico da Bacia do Amazonas (Cunha et al., 1994) e das correlações regionais, utilizandose os perfis geofísicos dos poços e o arcabouço bioestratigráfico então disponível para o Devoniano da bacia (Melo et al., 1996a, b), elaborou-se um arcabouço geocronológico com suporte na moderna Estratigrafia de Seqüências (Cunha, 2000) (fig. 15).

$\mathrm{O}$ método de análise estatística aplicado foi semelhante àquele descrito por Azambuja Filho (1994). De início, o perfil de raiosgama, correspondente ao intervalo analisado (Seqüência Urupadi-3) (Cunha, 2000), foi dividido em diferentes subintervalos que apresentavam domínios com iguais taxas de acumulação ao longo da história deposicional dessa seqüência (fig. 16).

Baseado nos dados bioestratigráficos da bacia, relativos ao intervalo em estudo, estimaram-se as taxas de acumulação nos poços estudados. Essas taxas serviram de base para a comparação com as obtidas pelas análises espectrais e para a escolha da mais pertinente nessas análises (fig. 17).

O conteúdo de freqüências dos periodogramas (fig. 18) é obtido através do programa "Statistics for Windows". Com os valores de espessuras obtidos, construiu-se uma matriz de correlação. Comparou-se essa matriz com a matriz das periodicidades dos ciclos de Milankovitch, identificando-se, através do programa Matrizes (CENPES), as razões com grau de similaridade superior ou igual a $95 \%$.

O passo seguinte foi identificar, no conjunto de dados gera- 


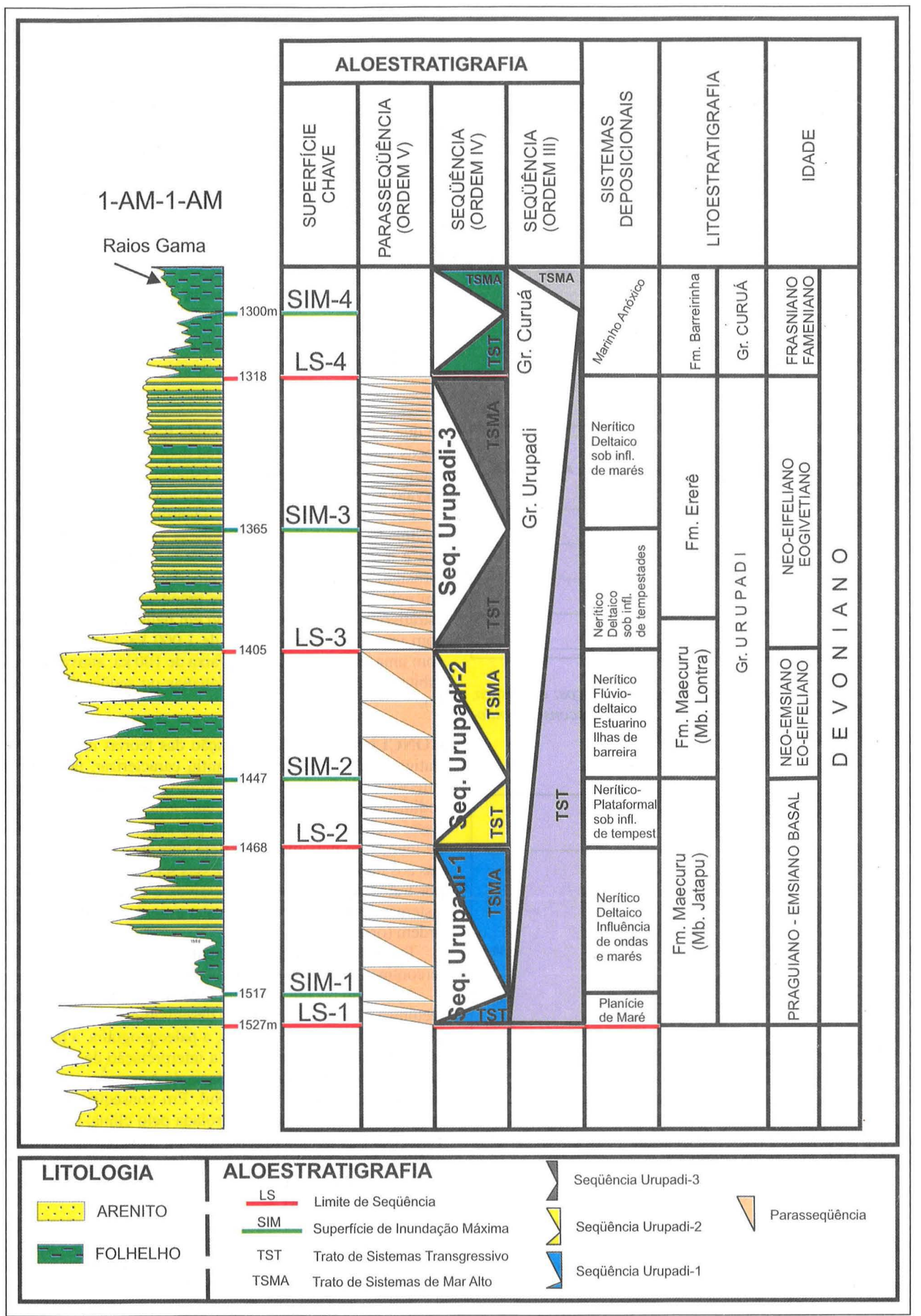

Figura 15 - Arcabouço cronoestratigráfico proposto para a Seqüência Eo- a Mesodevoniana da Bacia do Amazonas, com as seqüências de ordens III, IV e V (Cunha 2000). 


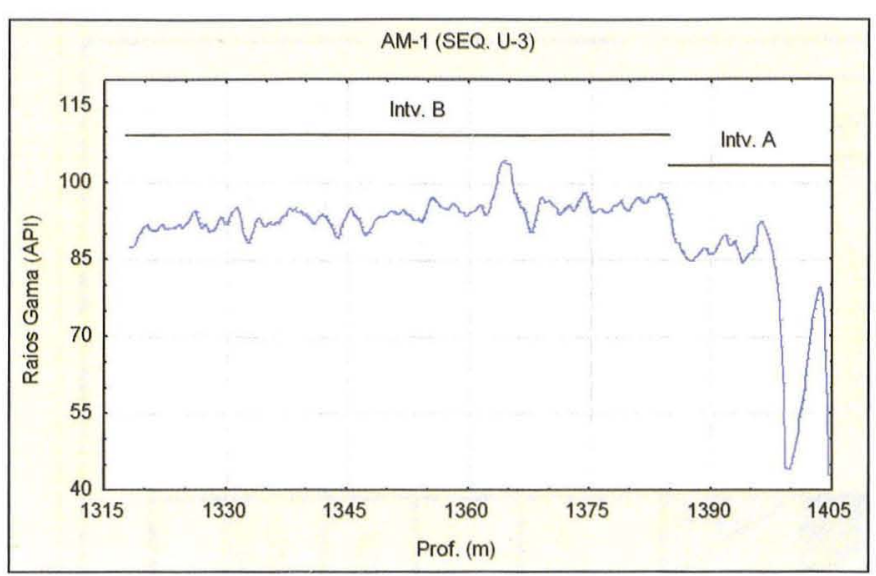

Figura 16- Intervalos definidos no poço e escolhidos para a análise espectral (Cunha 2000).

\begin{tabular}{|c|c|c|c|c|}
\hline $\begin{array}{c}\text { ZONA } \\
\text { PALINOLÓGICA }\end{array}$ & POÇO & $\begin{array}{c}\text { ESPESSURA } \\
(\mathrm{m})\end{array}$ & $\begin{array}{c}\text { DURAÇÃO } \\
\text { (Ma) }\end{array}$ & $\begin{array}{c}\text { TAXA DE } \\
\text { ACUMULAÇÃO } \\
(\mathrm{cm} / \mathrm{ka})\left(^{*}\right)\end{array}$ \\
\hline \multirow{2}{*}{$\begin{array}{c}\text { "V" } \\
\text { ou } \\
\text { "AD" }\end{array}$} & AM-1 & 87 & & 2,49 \\
\cline { 2 - 3 } & UA-1 & 140 & \multirow{2}{*}{3,5} & 4,00 \\
\cline { 2 - 3 } & MS-4 & 111 & & 3,17 \\
& UI-2 & 81 & & 2,31 \\
\hline
\end{tabular}

Figura 17- Resumo dos dados utilizados dos poços: espessura, duração da biozona e taxa de deposição; (*) desconsiderandose efeito de compactação (Cunha, 2000).

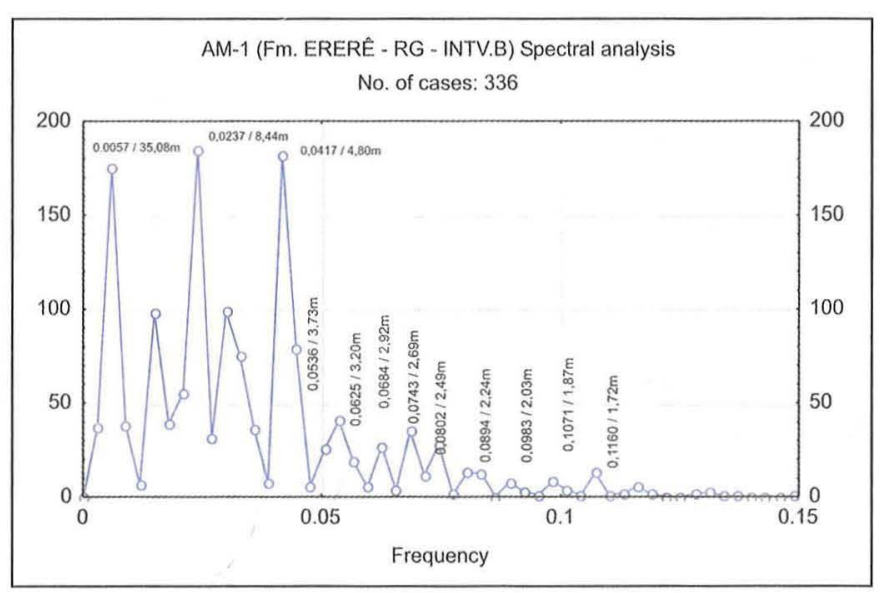

Figura 18-Análise espectral do perfil de raios-gama de parte da seção estudada (Cunha, 2000).

dos, o melhor comprimento de onda que se adequasse a uma taxa de acumulação apropriada ou mais coerente e, desta forma, definir a duração de cada ciclo, os quais, neste caso particular, correspondem a ciclos de $100 \mathrm{ka}$.

Finalmente, contaram-se quantos ciclos havia em cada segmento (31), e multiplicou-se esse número pela duração de cada ciclo (100 ka) obtendo-se então a duração temporal de todo o intervalo analisado (intervalo B, no caso, 3,1 Ma). Observou-

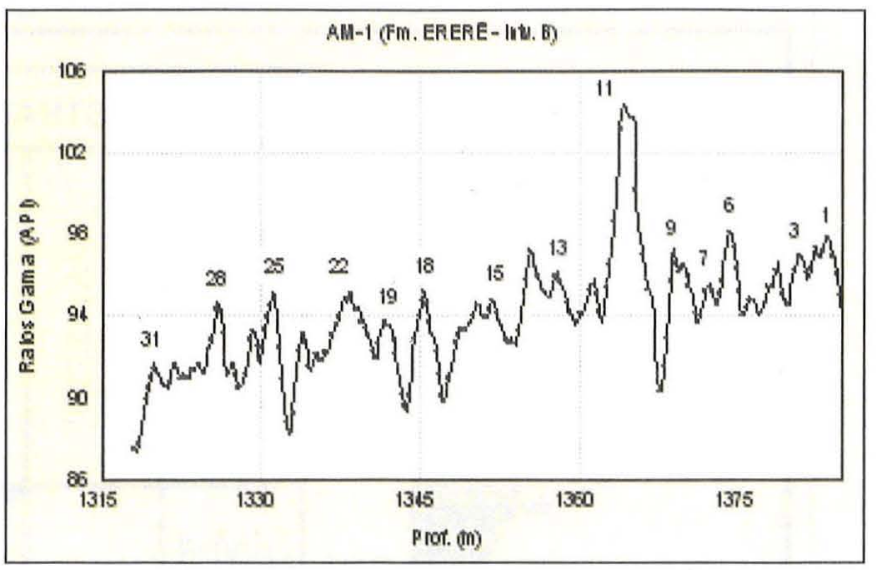

Figura 19- Perfil de raios-gama com a contagem do ciclos de $100 \mathrm{ka}$ (Cunha, 2000).

se que a duração total assim obtida ficou sempre, em todos os poços analisados, muito próxima daquela estimada pela bioestratigrafia (3,1 Ma no intervalo estudado $\mathrm{B}$, mais 0,4 Ma no intervalo $\mathrm{A}$, resultando em 3,5 Ma no intervalo total) (fig. 19).

Foi possível, desta forma, identificar ciclos siliciclásticos modulados por oscilações climáticas, principalmente relacionados a movimentos de excentricidade curta da órbita terrestre, tornando possível o refinamento do arcabouço estratigráfico em pelo menos uma ordem de grandeza. Assim, o arcabouço estratigráfico existente, baseado em palinomorfos (miósporos), com uma resolução de cerca de $1.000 \mathrm{ka}$, passa a ser aferido com uma resolução maior, na faixa de $100 \mathrm{ka}$, através dos ciclos orbitais (parasseqüências, ciclotemas ou seqüências de ordem V).

CONCLUSÕES A utilização das teorias da moderna Estratigrafia de Seqüências permitiu caracterizar, no Devoniano Inferior e Médio da Bacia do Amazonas, ciclos ou seqüências sedimentares e hierarquizá-los em várias ordens (ordens I a V). Esses ciclos são bem definidos por superfícies-chave como as de inundação máxima, superfície transgressiva, e as relacionadas aos limites de seqüências. Essas seqüências são constituídas por tratos de sistemas transgressivos e de mar alto; o trato de sistemas de mar baixo parece estar ausente, nos ciclos de maior ordem (ordem IV).

Todas as seqüências apresentam correlação regional e até intercontinental (bacias do Parnaíba e de Murzuk, na Líbia).

Apesar do pacote sedimentar estudado ter sofrido influência tectônica e eustática durante o desenvolvimento de sua edificação, os indicadores litológicos, a paleogeografia, a paleobiota e a paleoclimatologia suportam a interpretação de que, nos tempos eo- a mesodevonianos, a Bacia do Amazonas esteve situada entre os paralelos $48^{\circ}$ e $57^{\circ}$ Sul. Em conseqüência, sua sedimentação era fortemente controlada pelo clima, sob efeito das variações dos parâmetros orbitais de Milankovitch, conforme análises espectrais dos perfis geofísicos de poços da bacia, utilizando-se os estudos da Cicloestratigrafia nas suas seqüências de ordem V (ciclotemas).

Através da Cicloestratigrafia, foram identificados ciclos siliciclásticos (de ordem V ou ciclotemas) modulados por oscilações climáticas principalmente relacionadas aos movimentos de excentricidade curta da órbita terrestre.

A duração temporal desses ciclos (ou parasseqüências, de ordem V) foi obtida através das análises espectrais e da geração e interpretação dos "periodogramas", que é uma metodologia capaz de detectar ciclicidades regulares nos conjuntos de dados 
classificados como séries de tempo (no caso, espessura de rocha associada ao tempo). Tais ciclicidades foram interpretadas como de natureza orbital, e mostraram intervalos regulares de $100 \mathrm{mil}$ anos $(100 \mathrm{ka})$ relacionados às variações da excentricidade curta da órbita terrestre.

Assim, o arcabouço cronoestratigráfico anteriormente existente, baseado em palinomorfos, com uma resolução de cerca de $1.000 \mathrm{ka}$, passa a contar, agora, com resolução bem maior, na faixa de $100 \mathrm{ka}$, graças ao estudo das parasseqüências, ou seqüências de quinta ordem, aqui apresentado.
Em resumo, podemos afirmar que, a despeito da moderna Estratigrafia de Seqüências ter sido elaborada a partir de seções estratigráficas relacionadas às margens passivas, pode-se utilizá-la no interior cratônico, tendo-se o cuidado de respeitar as particularidades que lhe são inerentes e a hierarquia das sequiências e de seus fractais, nem sempre globalmente síncronos.

O uso da Cicloestratigrafia na análise de sequiências de maior ordem apresentou boa resposta. $\mathrm{O}$ método pode e deve ser utilizado nas bacias sedimentares interiores, independente de suas características estruturais.

\section{Referências}

Azambuja Filho N.C. 1994. Cicloestratigrafia como refinamento estratigráfico. In: SBG, Congresso Brasileiro de Geologia, 38, Boletim de Resumos Expandidos, v. 1, p. 585-586.

Castro A.H.A. 1999. Estudo de ciclicidade orbital com base em dados sísmicos (exemplo para o Mioceno da Bacia de Campos, SE do Brasil). Dissertação de Mestrado, Instituto de Geociências, Universidade Federal do Rio Grande do Sul, 147p

Cecil C.B. 1990. Paleoclimate controls on stratigraphic repetition of chemical and siliciclastic rocks. Geology, 18:533-536.

Chang K.H. 1975. Concepts and terms of unconformity-bounded units of distinct category. Geological Society of America Bulletin, 86:1544-1552.

Coutinho L.F.C. \& Gonzaga F.G. 1994. Evolução Tectonossedimentar e Termal da Bacia do Amazonas. Belém, Brasil - Petrobras - Relatório Interno.

Cunha P.R.C. 2000. Análise estratigráfica dos sedimentos eo-mesodevonianos da porção ocidental da Bacia do Amazonas sob a ótica da Estratigrafia de Seqüências no interior cratônico. Dissertação de Mestrado, Instituto de Geociências, Universidade Federal do Rio Grande do Sul, 263p.

Cunha P.R.C., Gonzaga F.G., Coutinho L.F.C., Feijó F.J. 1994. Bacia do Amazonas. Boletim de Geociências da Petrobrás. Rio de Janeiro, Brasil, v. 8, n. 1, pp.:47-55.

Einsele G. \& Ricken W. 1991. Introductory remarks - Part II Larger cycles and sequences. In: Einsele G., Ricken W. \& Seilacher A. (eds.). Cycles and Events in Stratigraphy. Berlin: Springer-Verlag, pp.:611-616.

Einsele G., Ricken W. \& Seilacher A. 1991. Cycles and Events in Stratigraphy - Basic Concepts and Terms - Introduction. In: Einsele G., Ricken W. \& Seilacher A. (eds.). Cycles and Events in Stratigraphy. Berlin: Springer-Verlag, pp.:1-19.

Gradstein F., Ogg J., Smith A. (Eds.) 2004. A geologic time scale. $3^{\text {rd }}$ ed. Cambridge University Press, Cambridge, xix +589 pp.

Fischer A.G. 1986. Climatic rhythms recorded in strata. Annual Review of the Earth and Planetary Sciences, 14:351-376.

Hays J.D., Imbrie J., Schakleton N.J. 1976. Variation in the Earth's orbit: pacemaker of the ice ages. Science, 194:1121-1132.

Johnson J.G., Klapper G. \& Sandberg C.A. 1985. Devonian eustatic fluctuations in Euramerica. Geological Society of America Bulletin, 96:567-587.

Melo J.H.G., Barrilari I.M.R., Loboziak S., Grahn T. \& Steemans P. 1996a. Resultados de solicitação de análise palinológica em amostras do Devoniano Inferior da Bacia do Amazonas. Petrobras/ Cenpes-Divex-Sebipe

Melo J.H.G., Loboziak S., Rodrigues R., Streel M., Quadros L.P. \& Barrilari I.M.R. 1996b. Age and correlation of the Barreirinha Formation (Curuá Group, Amazon Basin): new evidence from the misopore biostratigraphy. Petrobras / Cenpes / Sebipe. Comunicação Técnica, 10p.

Miall A.D. 1997. The Geology of Stratigraphic Sequences. SpringerVerlag Berlin Heidelberg, 433pp.

Milankovitch M.M. 1941. Canon of insolation and ice-age problem. Koniglich Serische Akademie, Belgrad, 133pp.

Miura K., Thomaz Filho A., Cunha F.M.B., Della Fávera J.C. 1983. Reavaliação das Possibilidades Petrolíferas da Bacia do Médio Amazonas. Rio de Janeiro, Brasil - Petrobrás / Depex - Relatório Interno.

Perlmutter M.A., \& Matthews, M.D. 1989. Global cyclostratigraphy - a model. In: Cross T.A. (ed.). Quantitative Dynamic Stratigraphy. London: Prentice Hall, pp.:233-260.

Scotese C.R. \& Barret S.F. 1990. Gondwana's movement over the South Pole during the Paleozoic: evidence from lithological indicators of climate. In: W.S. McKerrow \& C.R. Scotese (eds.) Palaeozoic Palaeogeography and Biogeography. The Geological Society of London Memoir, 12, pp.:75-86.

Sloss L.L. 1963. Sequences in the Cratonic Interior of North America. Geological Society of America Bulletin, 100:1661-1665.

Vail P.R.; Mitchum Jr. R.M. \& Thompson III S. 1977. Seismic Stratigraphy and Geological Changes of Sea Level from Coastal Onlap. In: Payton C.E. (ed.) Seismic Stratigraphy - Applications to Hy drocarbon Exploration, pp.:63-81, American Association of Petroleum Geologists Memoir, 26.

Vail P.R., Audemard F., Bowman S.A., Eisner P.N. \& Perez-Cruz C 1991. The stratigraphic signatures of tectonics, eustacy and sedimentology - an overview. In: Einsele G., Ricken W. \& Seilacher A. (eds.). Cycles and Events in Stratigraphy. Berlin: Springer-Verlag, pp.:617-659.

Wilgus C.K., Hastings B.S., Kendal C.G.S.C., Posamentier H.W., Ross C.A. and Van Wagoner J.C. 1988. Sea Level Changes: an integrated approach. Tulsa, Oklahoma, 407pp. Society of Economic Paleontologists and Mineralogists, Special Publication, 42.

Williams K.E. 1995. Tectonic Subsidence Analysis and Paleozoic Paleogeography of Gondwana, In: A.J. Tankard, R. Suarez and H.J. Welsink (eds.). Petroleum Basins of South America, pp.:79-100. American Association of Petroleum Geologists Memoir, 62 
